\title{
LCL Topology Based Single Stage Boost Rectifier Topology for Wireless EV Charging
}

\author{
Sweya Sasikumar and K. Deepa* \\ Department of Electrical and Electronics Engineering, \\ Amrita School of Engineering, Bengaluru, Amrita Vishwa Vidyapeetham, India \\ E-mail: sweyasasikumar@gmail.com; k_deepa@blramrita.edu \\ ${ }^{*}$ Corresponding Author
}

Received 04 June 2018; Accepted 26 November 2018; Publication 12 December 2018

\begin{abstract}
Research into Wireless power transfer, its applications and adoption is currently growing at a rapid rate. Wireless Power Transfer (WPT) provides a lot of advantages and serves as a solution to the drawbacks of wired power transfer techniques. Research nowadays is focused on developing an inductive power transfer module for transferring power wirelessly. In order to improve the efficiency and the range of power transfer, new coil structures and design schemes for wireless power transfer have been introduced. This paper provides a comparative study of a WPT circuit with a boost rectifier circuit and another with a single-stage boost rectifier circuit, with focus on reducing switching losses and complexity. The DC side inductor and switch of the boost circuit is replaced with an AC side inductor to overcome the disadvantages of boost circuit. For each circuit explained in this paper, Matlab simulation results of output voltage, current and efficiency are analyzed and presented.
\end{abstract}

Keywords: Wireless power charging, Electric vehicle (EV), Inductive power transfer (IPT), Coupled coils.

Journal of Green_Engineering, Vol. 8_4, 573-596. River Publishers

doi: $10.13052 /$ jge1904-4720.845

This is an Open Access publication. (c) 2018 the Author(s). All rights reserved. 
574 Sweya Sasikumar and K. Deepa

\section{List of Abbreviations}

$\begin{array}{ll}\text { EV } & \text { Electric Vehicle } \\ \text { IPT } & \text { Inductive Power Transfer } \\ \text { SIPT } & \text { Static Inductive Power Transfer } \\ \text { DIPT } & \text { Dynamic Inductive Power Transfer } \\ \text { DC } & \text { Direct Current } \\ \text { AC } & \text { Alternating Current }\end{array}$

\section{Introduction}

The world is facing major problems today, such as global warming due to high carbon emissions, climate variations, increased temperatures, pollution etc. and most of them point to the use of fossil fuels for energy production and transport as the root cause. Transport is a huge global industry. In order to gradually reduce and eliminate the carbon footprint from the Transport industry, Electric Vehicles (EVs) are being promoted as a viable, clean and safe alternative for transport [1].

Electric Vehicles (EVs) run on charged batteries and battery design is complex in nature, involving identification of battery specifications for various parameters such as energy density, power density, weight and cost. Among the existing battery technologies, Lithium-ion batteries are better suited and are hence preferred for EVs. As of today, EV battery charging is mainly done through a connected medium. It consumes a lot of time and providing a wellconnected charging infrastructure for EVs requires a lot of capital investment and maintenance.

Wireless charging, on the other hand, has many advantages over wired charging. It has the potential to simplify and solve the charging infrastructure issues to a large extent. Wireless charging has therefore garnered a lot of interest and is attracting a lot of research in various areas of applications including transport. Inductive Power Transfer (IPT) for EVs is a rapidly evolving technology meant to charge the EV battery using stationary charging (for a parked vehicle), opportunity charging (for vehicles that have temporary stopped, for example, at traffic signals or bus stops), both of these can be categorized into Static charging and the other is dynamic charging (when the vehicle is in motion on a dedicated lane equipped with an IPT system) $[16,17]$. Inductive power transfer (IPT) being a wireless power transfer system is a promising futuristic technology with applications in various fields like 
medical [2, 3], domestic and industrial [4-6] and [12, 13]. There are no wired connections between the primary and secondary in the IPT model [7-9].

IPT systems can thus be divided into two main types: Static IPT system (SIPT) and Dynamic IPT system (DIPT). In a SIPT system the vehicle is charged at the parking station itself. The main disadvantage of this system is in maintaining the availability of sufficient parking space for the duration of charging. In a DIPT system, the EV is charged while in motion, through a charging station present underground. The dynamic IPT system is the preferred technique due to better efficiency.

To deploy WPT in EV, the power is supplied by the primary coil (transmitter), which is part of the charging unit, while the secondary side (receiver) is present under the EV. The DC power at the supply side is inverted to AC, and using a coupling circuit, the power is supplied to the load. The AC power at the receiver coil is rectified to obtain a DC voltage, which is then used to charge the battery $[10,11]$. The EV also has compensation networks that act as a band pass filter to reduce all noise frequency components.

This paper aims to introduce a comparative study of three circuits: double secondary circuit, single secondary circuit $[14,15]$ and the proposed single stage boost rectifier circuit. The efficiency and loss components are also calculated and analyzed. The Matlab simulation results and hardware implementation details of the circuits are presented and analyzed in Section 4, 5 and 6.

\section{System Explanation}

Inductive power transfer (IPT) system is modeled to transfer power wirelessly from the primary source to the secondary load side through electromagnetic induction process. The IPT system at the primary side contains an inverter circuit which is accompanied by a primary coupled coil and secondary coil where in the secondary coil transfers power to the load side. On the secondary side, the $\mathrm{AC}$ voltage is then rectified to $\mathrm{DC}$ and is followed by a boost converter to increase the voltage.

In [1] the IPT system has one primary and two secondary coils. The power transfer is made through the two secondary coils to the load as shown in Figure 1.

The circuit shown in Figure 1 has disadvantages such as increased switching losses, complexity and more number of switches. So to overcome this 


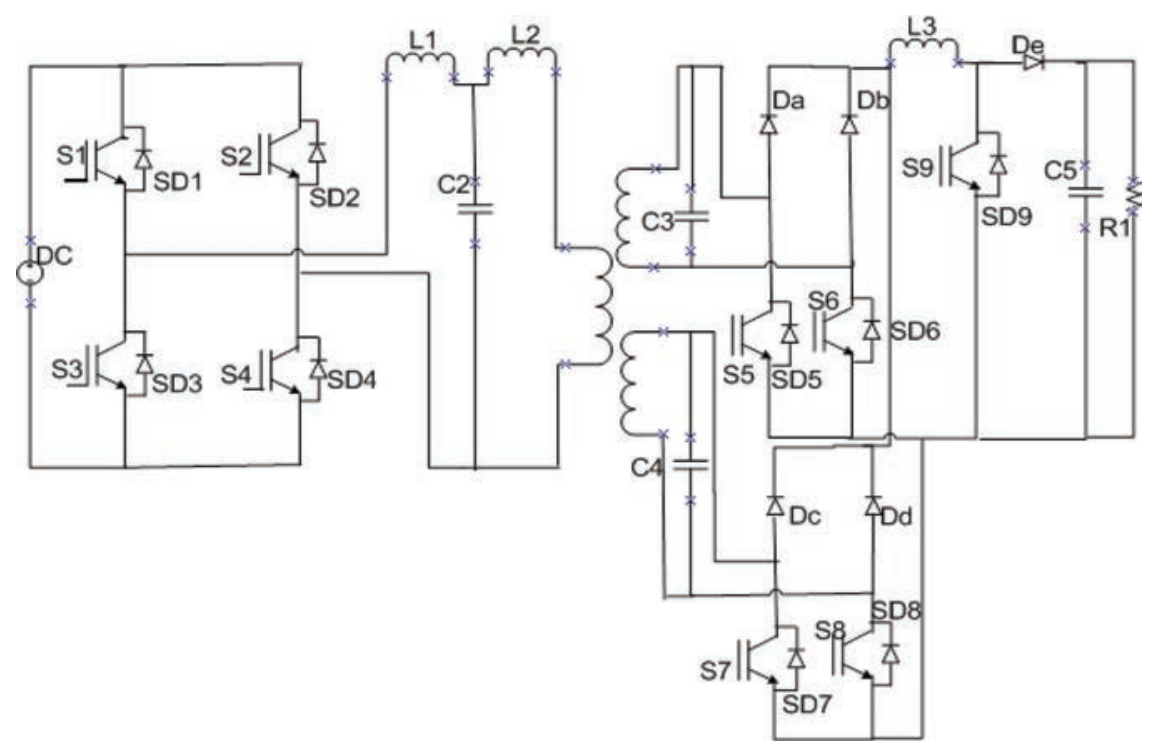

Figure 1 LCL primary topology with two secondary coils.

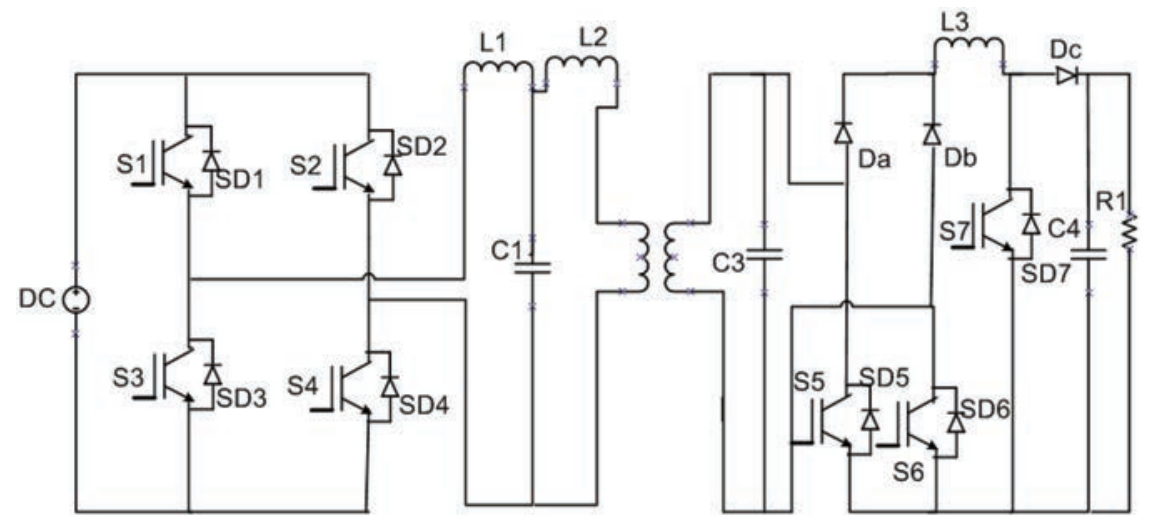

Figure 2 LCL primary and C secondary topology.

disadvantage a topology with single secondary side is considered. The boost circuit used in Figures 1 and 2 also contributes to switching losses. In order to reduce switching losses in the boost circuit, a single stage boost rectifier circuit is proposed as shown in Figure 3. The boost circuit is replaced by an inductor in the secondary coupling side as shown in Figure 3 and operated as single stage boost rectifier. 


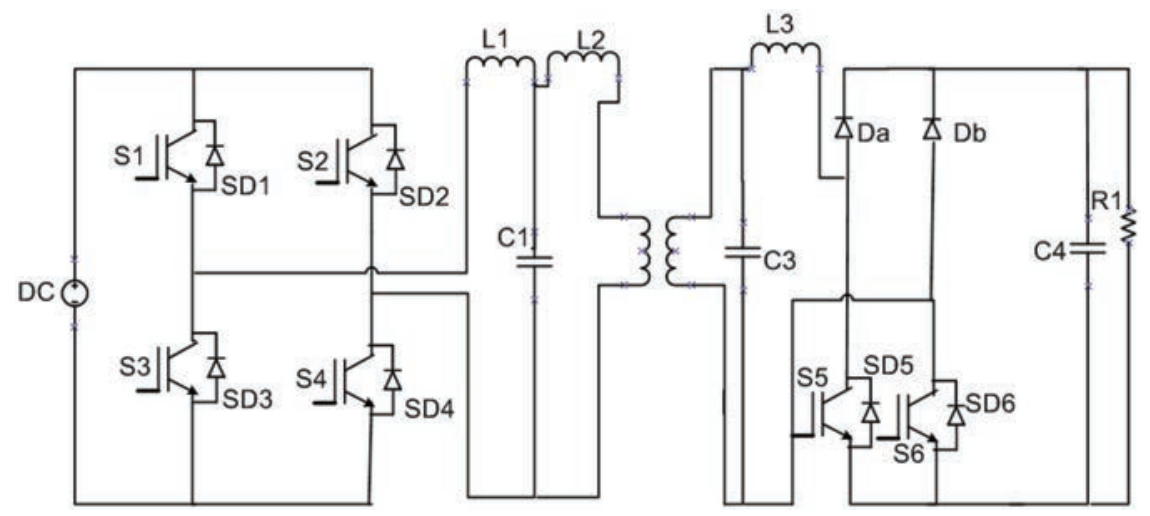

Figure 3 LCL primary and single stage boost rectifier C secondary topology.

The MOSFETs utilized in the circuits have inbuilt snubber capacitance, thus eliminating the need for an external capacitance in the secondary side. Figure 4 shows a topology with a single stage boost rectifier circuit, excluding the external capacitance in Figure 3, thus forming the proposed circuit for Wireless Power Transfer.

\section{Design and Operation}

The working of the proposed circuit shown in Figure 4 can be spilt into two parts: a Resonant DC-AC stage and a Boost Rectifier stage.

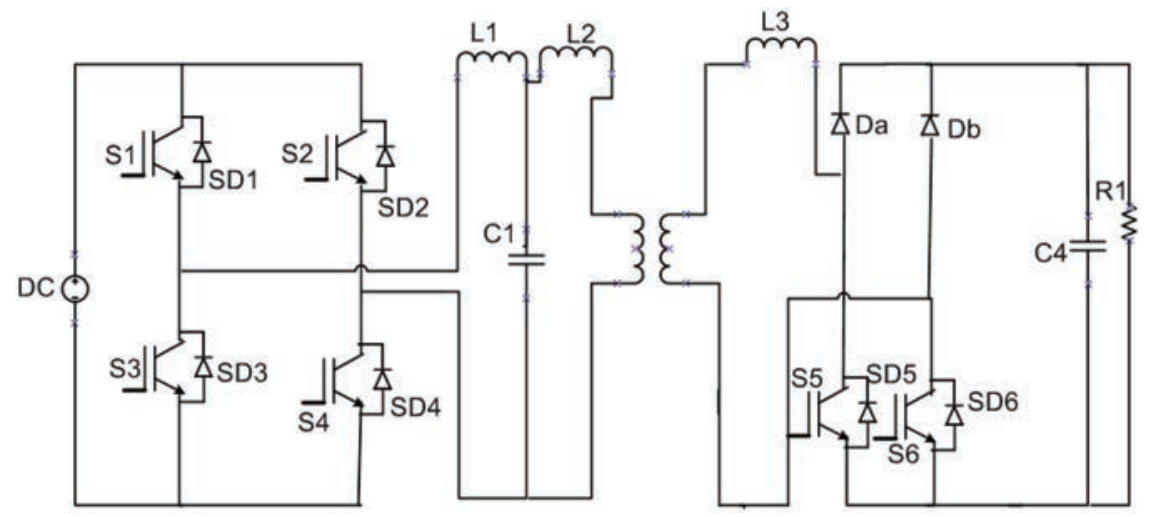

Figure 4 LCL primary and single stage boost rectifier secondary topology. 


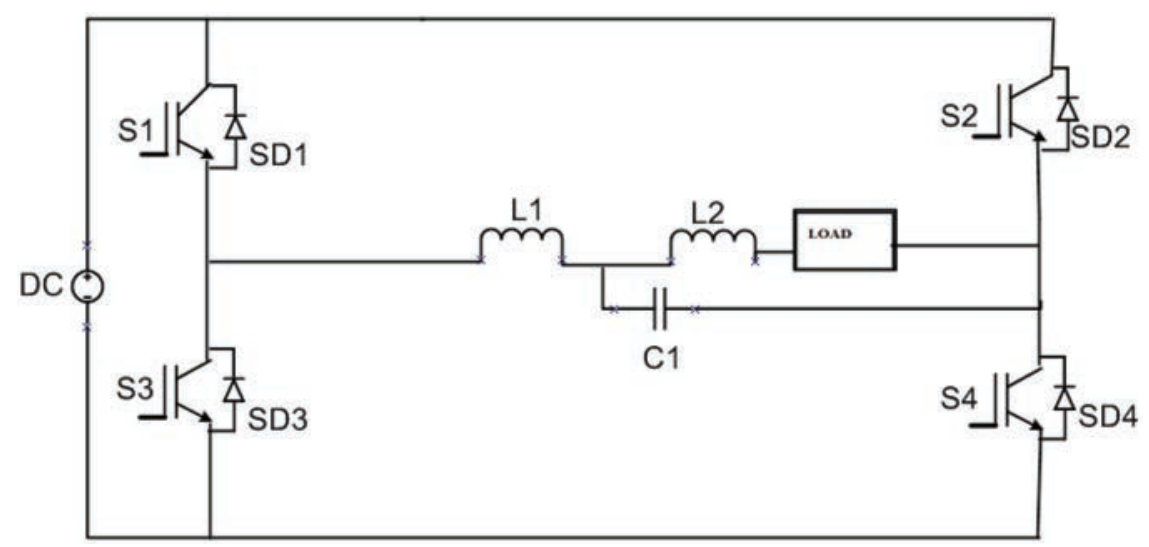

Figure 5 Resonant DC-AC inverter.

\subsection{Resonant DC-AC Inverter at the Primary Side}

The primary coil uses a resonant switched mode converter (LCL circuit) which exhibits a resonant behavior, resulting in a sinusoidal output. Theoretically the resonant converter has an efficiency of $100 \%$. But in practical use, due to switching and ohmic losses, the efficiency obtained is around 95-98\%. The resonant DC-AC network at the primary side is shown in Figure 5.

\section{Modes of operation}

The resonant DC-AC inverter circuit illustrated in Figure 5 operates in four modes.

Mode I: Switches S1 and S4 are switched ON. The flow of current in the closed path created is as shown in Figure 6(a). A positive voltage and current is obtained at the load side.

Mode II: Switches S1 and S4 are switched OFF. The diode SD3 and SD2 operates in freewheeling mode and the current flows from load to source as shown in Figure 6(b).

Mode III: This mode is similar to mode I. Switches S2 and S3 are switched $\mathrm{ON}$. The direction of current and the voltage is negative. The flow of negative current in the load is shown in Figure 6(c).

Mode IV: This mode is similar to mode II. Switches S2 and S3 are switched OFF. The diodes SD4 and SD1 freewheels the current to source as shown in Figure 6(d). 


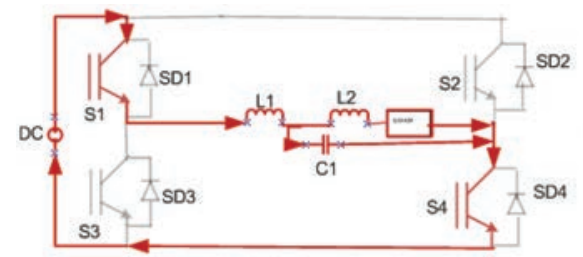

(a) Model

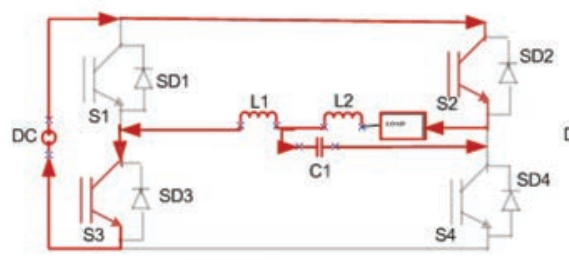

(c) ModellI

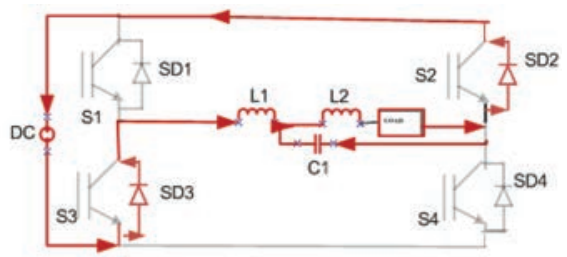

(b) Mode II

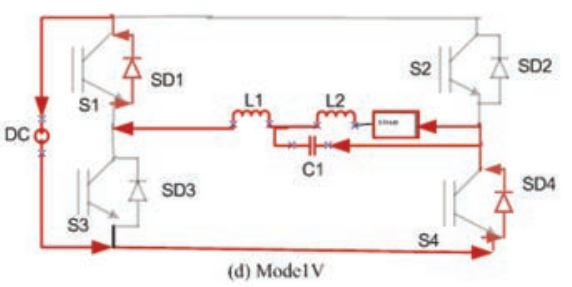

Figure 6 Modes of operation at primary side.

\subsection{Boost Rectifier at the Secondary Side}

The secondary side consists of a single stage boost rectifier which supplies the DC voltage to the load side. In this topology, the boost switch and diode are removed and a boost inductor is added to the rectifier circuit.

\section{Modes of operation}

The boost rectifier circuit illustrated in Figure 7 operates in four modes (shown in Figure 8). The first two modes contribute the positive cycle of the output and second two modes contribute the negative cycle.

Mode I: Switches S5 and S6 are switched ON. The input side inductor L3 is connected in parallel with the source, and hence the inductor charges to supply voltage.

Mode II: Switches S5 and S6 are switched OFF. The supply current now freewheels through diode Da and SD6. The voltage across the supply and inductor appears across the load.

Mode III: This mode is similar to Mode I, except the direction of flow of supply current is in the opposite direction. In this mode, switches S6 and S5 are turned $\mathrm{ON}$ and the current flows through S6, SD5, L3 and source.

Mode IV: This mode is similar to Mode II, Switches S5 and S6 are turned OFF. The supply current now freewheels through diode Db and SD5. The voltage across the supply and inductor appears across the load. 


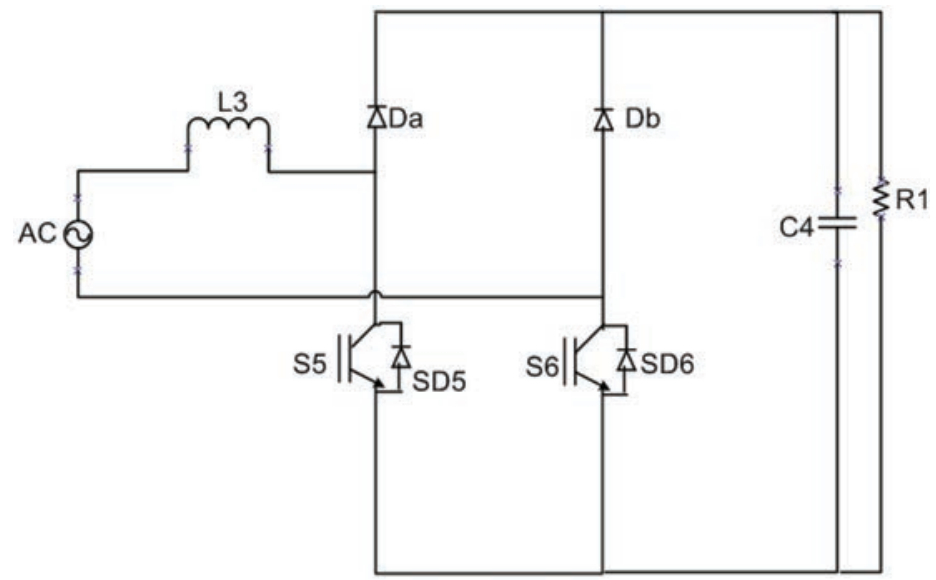

Figure 7 Boost rectifier circuit.
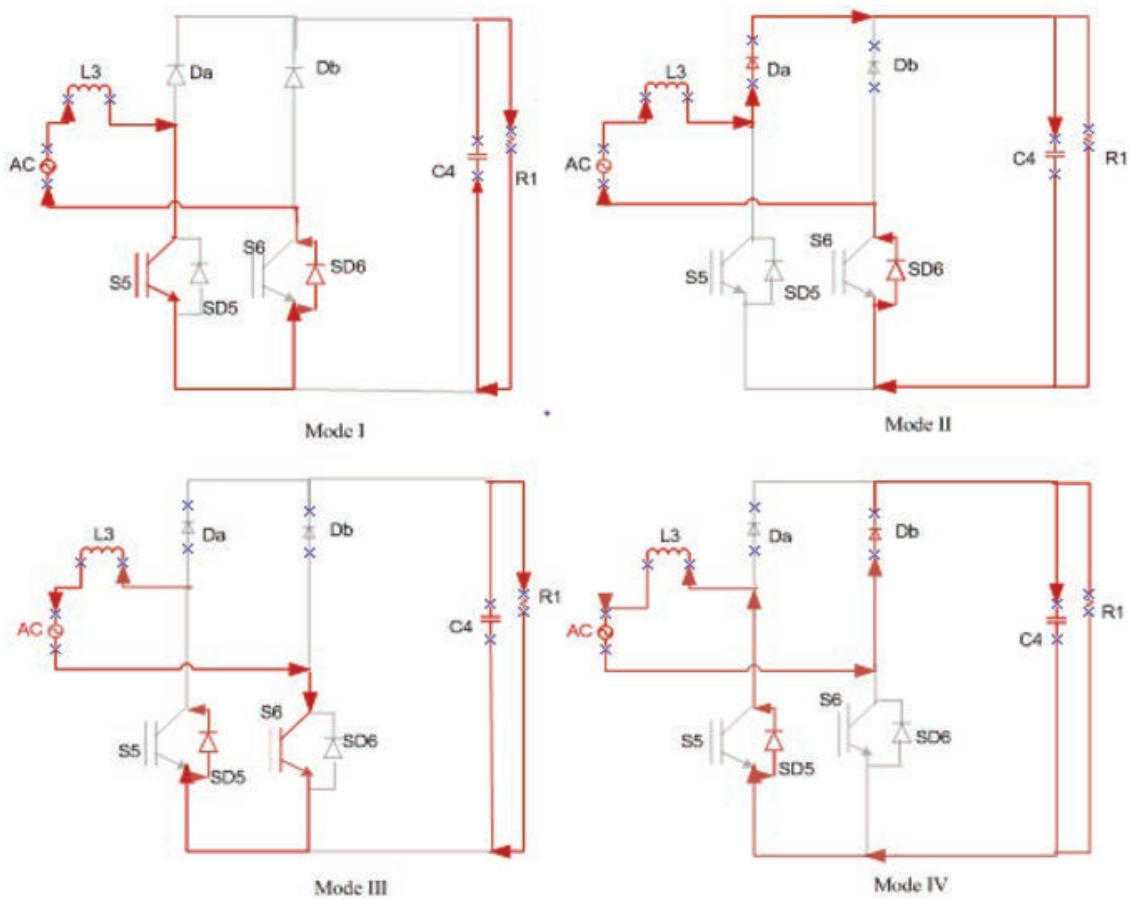

Figure 8 Modes of operation at secondary side. 


\subsection{Design of LCL Filter}

Power $P_{O}=500 \mathrm{~W}$

Output voltage $V_{O}=200 \mathrm{~V}$

Output current $I_{O}=\frac{P_{O}}{V_{O}}=2.5 \mathrm{~A}$

The resonant frequency range is given by:

$$
f_{\text {res }} \geq 2 f_{s w}
$$

Therefore, Resonant frequency $f_{\text {res }}=100 \mathrm{kHz}$

$$
\omega_{\text {res }}=2 \pi f_{\text {res }}=200000 \pi
$$

Switching frequency $f_{s w}=50 \mathrm{kHz}$

$$
\omega_{g}=\omega_{s w}=2 \pi f_{s w}=100000 \pi
$$

For maximum power transfer,

$$
\text { Base } \mathrm{Z}=\frac{\mathrm{V}_{\mathrm{o}}}{\mathrm{I}_{\mathrm{O}}}=80 \Omega
$$

The base capacitance $\left(\mathrm{C}_{\mathrm{b}}\right)$ is expressed as:

$$
C_{\mathrm{b}}=\frac{1}{\mathrm{~W}_{\mathrm{g}} \mathrm{Z}_{\mathrm{b}}}=397.8 \mu \mathrm{F}
$$

The rated current

$$
I_{\text {max }}=\frac{\sqrt{2} P_{o}}{V_{o}}=3.53 \mathrm{~A}
$$

A 10\% ripple in the rated current for the design parameters can be expressed as:

$$
\triangle I_{\max }=0.1 I_{\max }=0.353 \mathrm{~A}
$$

The primary capacitance $\mathrm{C}_{1}<0.05 \mathrm{C}_{\mathrm{b}}$

$$
\text { Therefore } \mathrm{C}_{1}=0.01 \mathrm{C}_{\mathrm{b}}=3.978 \mu \mathrm{F}
$$

The resonant inductance $L_{2}$ is given as,

$$
L_{2}=\frac{1}{C_{1} \omega_{s w^{2}}}=2.55 \mu \mathrm{H}
$$

The primary inductance is calculated as,

$$
\omega_{\text {res }}=\sqrt{\frac{L_{1}+L_{2}}{L_{1} L_{2} C_{f}}}
$$

Therefore the primary inductor $L_{1}=0.6 \mu \mathrm{F}$ 


\section{Simulation Results}

The proposed WPT topology is simulated in Matlab software. The power is transmitted through the coupled coil to the load. The simulation is carried out for all the four circuits. The first circuit (Figure 1) consists of a wireless system with two secondary coils, the second (Figure 2) has a single secondary, the third (Figure 3) has a single stage boost rectifier topology and the fourth one (Figure 4) is the proposed circuit with single stage boost rectifier and MOSFET internal capacitance.

The simulation parameters used for simulation are listed in Table 1.

Figure 9 illustrates the simulation circuit of the wireless power system with two secondary coils. The output voltage and current for this circuit is given in Figure 10. Figures 11 and 12 shows the simulation diagram of the inductive power system with a single secondary and the output voltage and current of the respective simulations.

Figure 13 exhibits the simulation of a single stage boost rectifier. The DC side inductor is replaced with an AC side inductor on the secondary coil side, which excludes the need for a separate boost circuit; thus eliminating switching losses in boost switch and diode. Figure 14 exhibits the output voltage and current of the boost rectifier circuit. In the proposed topology (Figure 15), the external capacitance in the secondary side is removed in the single stage boost rectifier circuit. Figure 16 exhibits the output voltage and current waveforms for the proposed topology.

Figures 17 and 18 illustrate the current and voltage waveforms across the storage elements. From the waveforms shown in Figures 10, 12, 14 and 16, the output voltage and current is found to be $400 \mathrm{~V}$ and 2 A respectively for all

Table 1 Simulation parameters

\begin{tabular}{|c|c|c|c|c|}
\hline & $\begin{array}{l}\text { IPT with Two } \\
\text { Secondary Coils }\end{array}$ & $\begin{array}{l}\text { IPT with One } \\
\text { Secondary }\end{array}$ & $\begin{array}{l}\text { IPT with Single } \\
\text { Stage Boost } \\
\text { Rectifier Circuit }\end{array}$ & $\begin{array}{l}\text { IPT with Single } \\
\text { Stage Boost } \\
\text { Rectifier Without } \\
\text { Capacitor in } \\
\text { Secondary }\end{array}$ \\
\hline$\overline{L_{1}}$ & $9.10 \mu \mathrm{F}$ & $9.10 \mu \mathrm{F}$ & $9.10 \mu \mathrm{F}$ & $9.10 \mu \mathrm{F}$ \\
\hline$L_{2}$ & $1 \mu \mathrm{F}$ & $1 \mu \mathrm{F}$ & $1 \mu \mathrm{F}$ & $1 \mu \mathrm{F}$ \\
\hline$\overline{C_{1}}$ & $1 \mu \mathrm{F}$ & $1 \mu \mathrm{F}$ & $1 \mu \mathrm{F}$ & $1 \mu \mathrm{F}$ \\
\hline$\overline{C_{3}}$ & $\begin{array}{l}1.5 \mu \mathrm{F} \text { (two } \\
\text { secondary coils) }\end{array}$ & $0.01 \mu \mathrm{F}$ & $0.3 \mu \mathrm{F}$ & Not applicable \\
\hline$\overline{L_{3}}$ & Not applicable & Not applicable & $0.5 \mathrm{mF}$ & $0.85 \mathrm{mF}$ \\
\hline
\end{tabular}




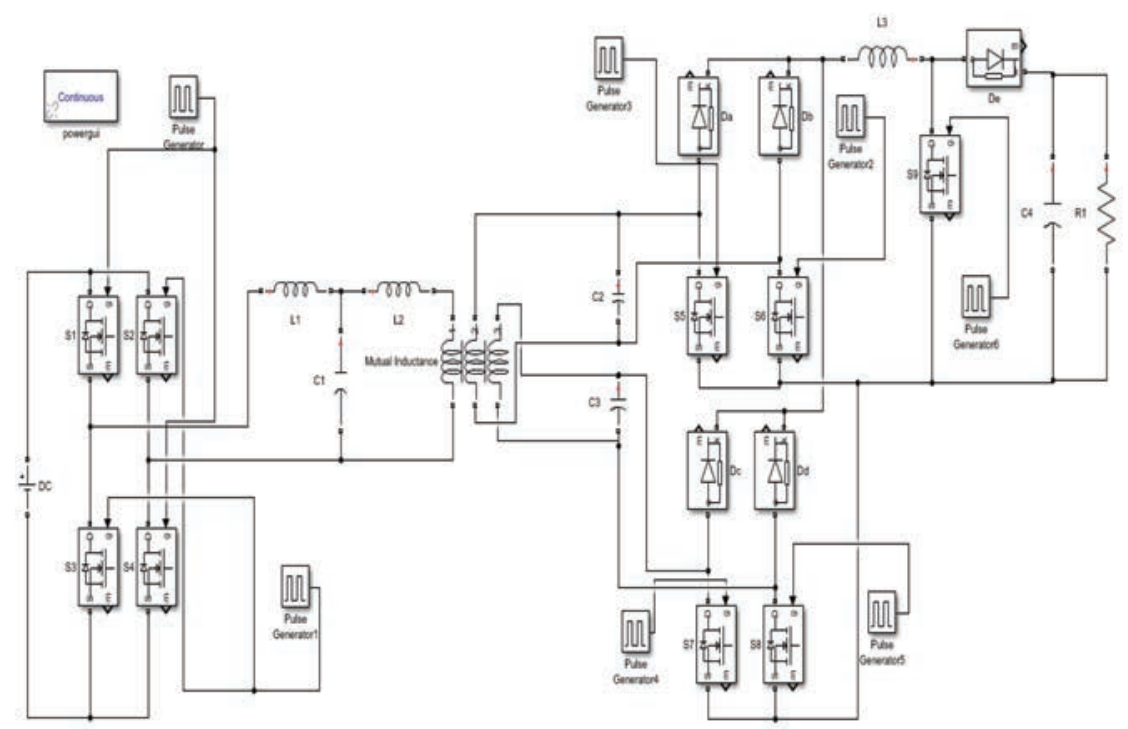

Figure 9 Simulation of wireless power system with two secondary coils.
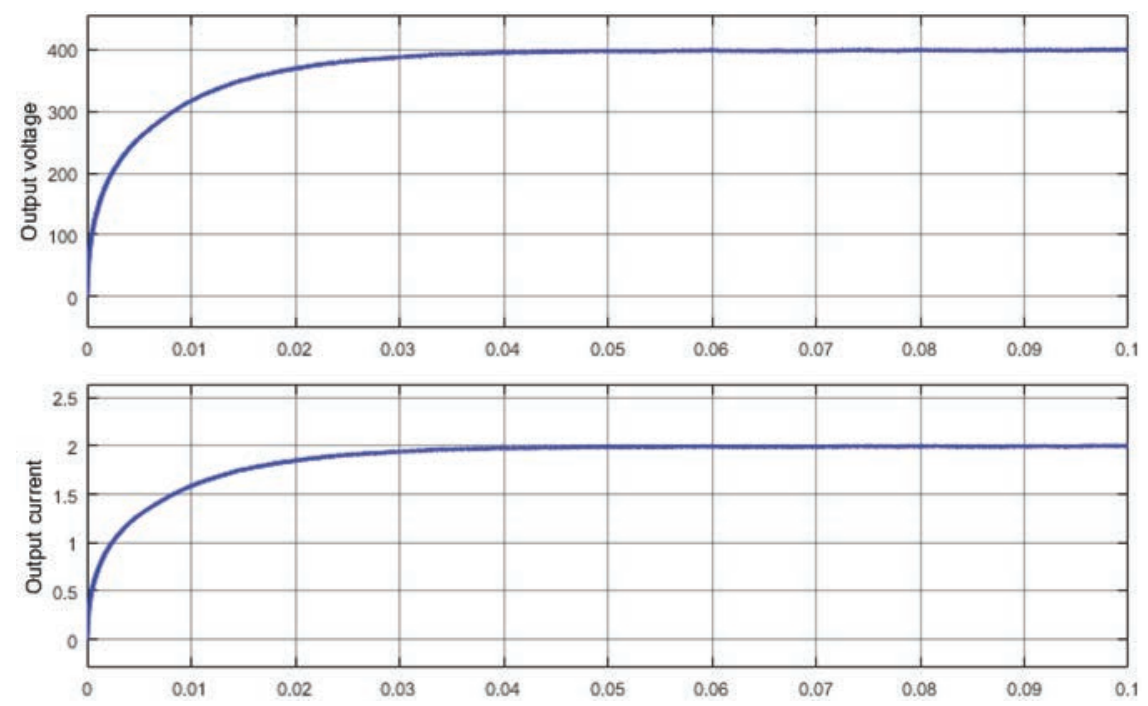

Figure 10 Output voltage and current with two secondary coils. 


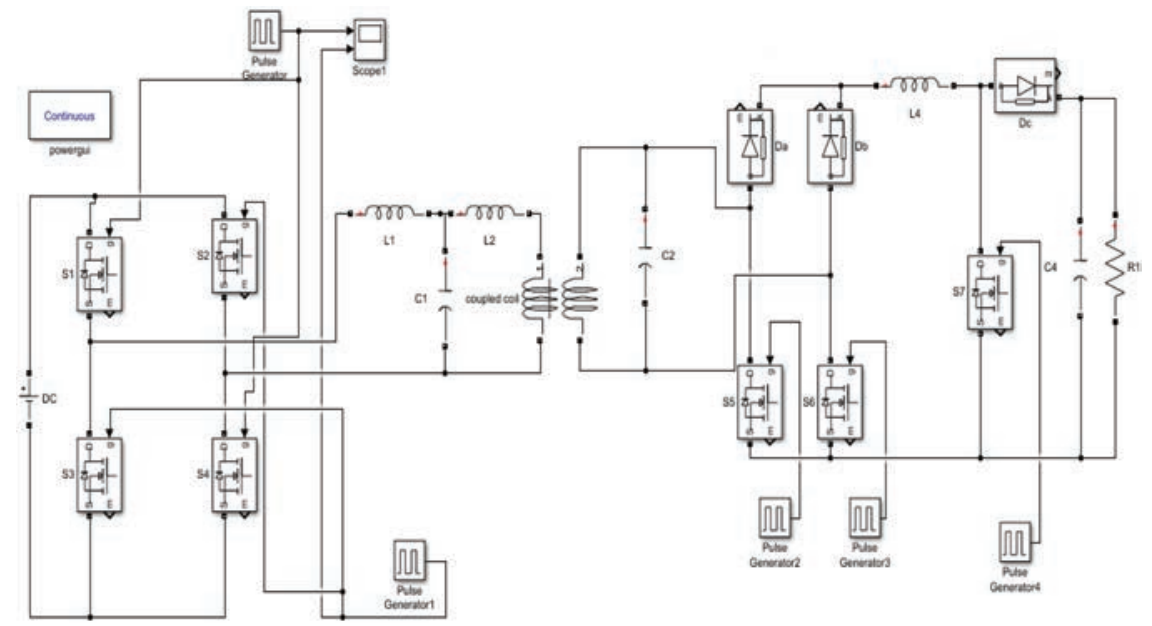

Figure 11 Simulation of inductive power transfer with single secondary.
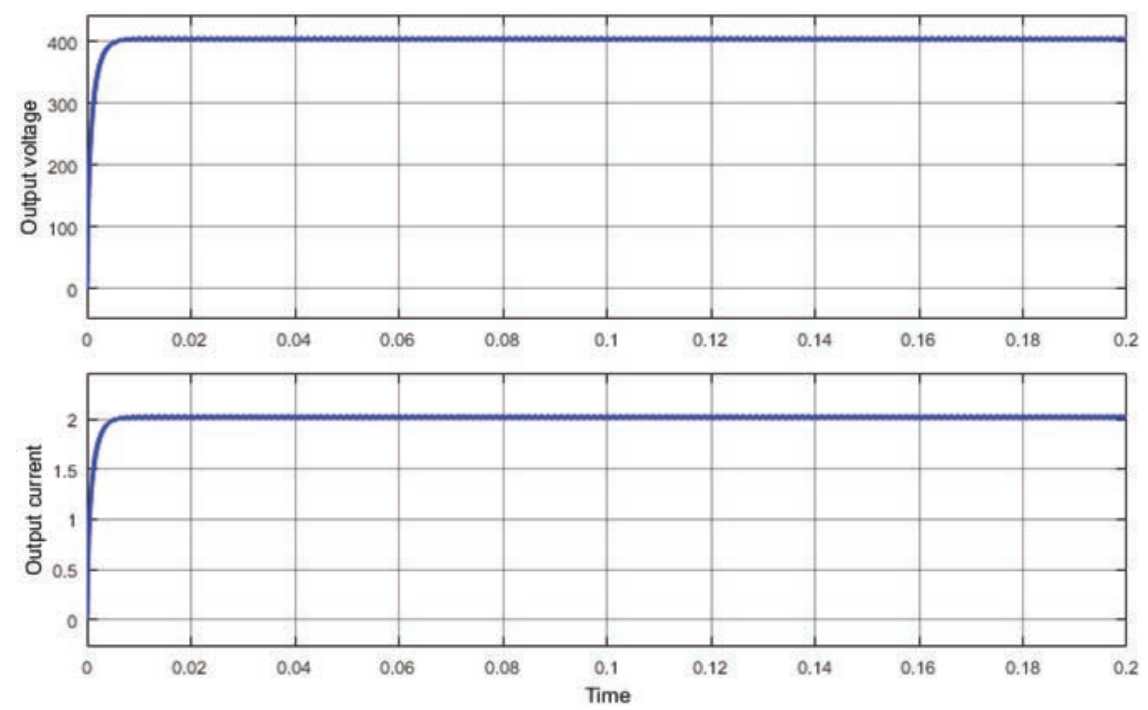

Figure 12 Output voltage and current with single secondary. 


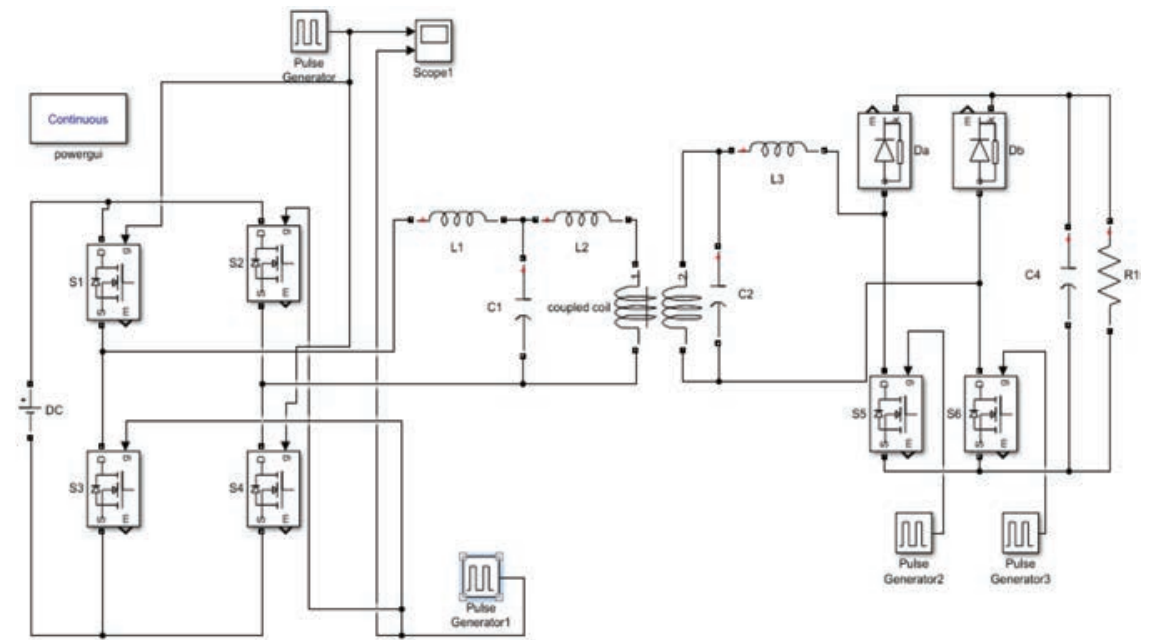

Figure 13 Simulation of inductive power transfer with single stage boost rectifier circuit.
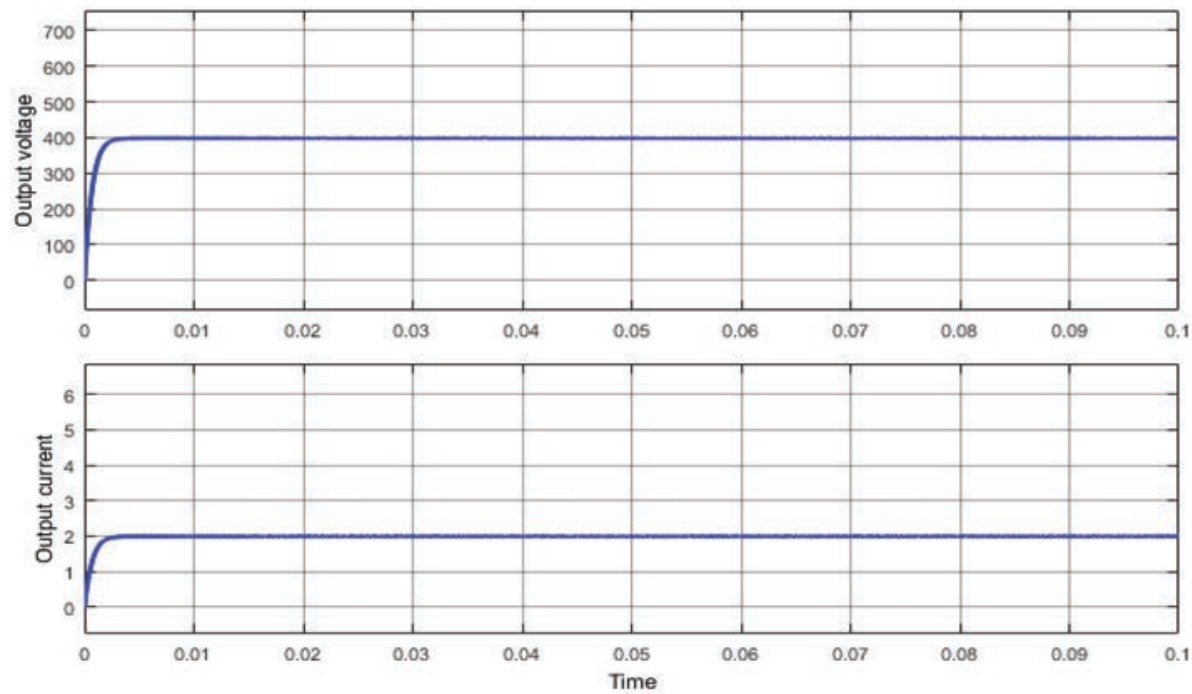

Figure 14 Output voltage and current with boost side rectifier circuit. 


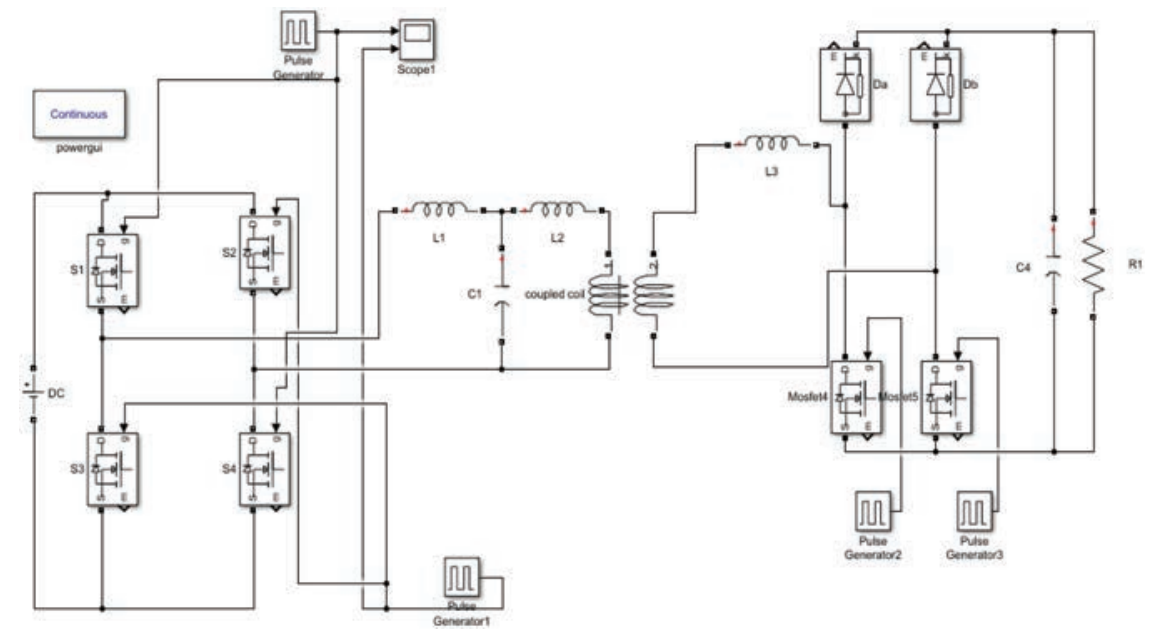

Figure 15 Simulation of inductive power transfer with single stage boost rectifier and MOSFET's internal capacitance.
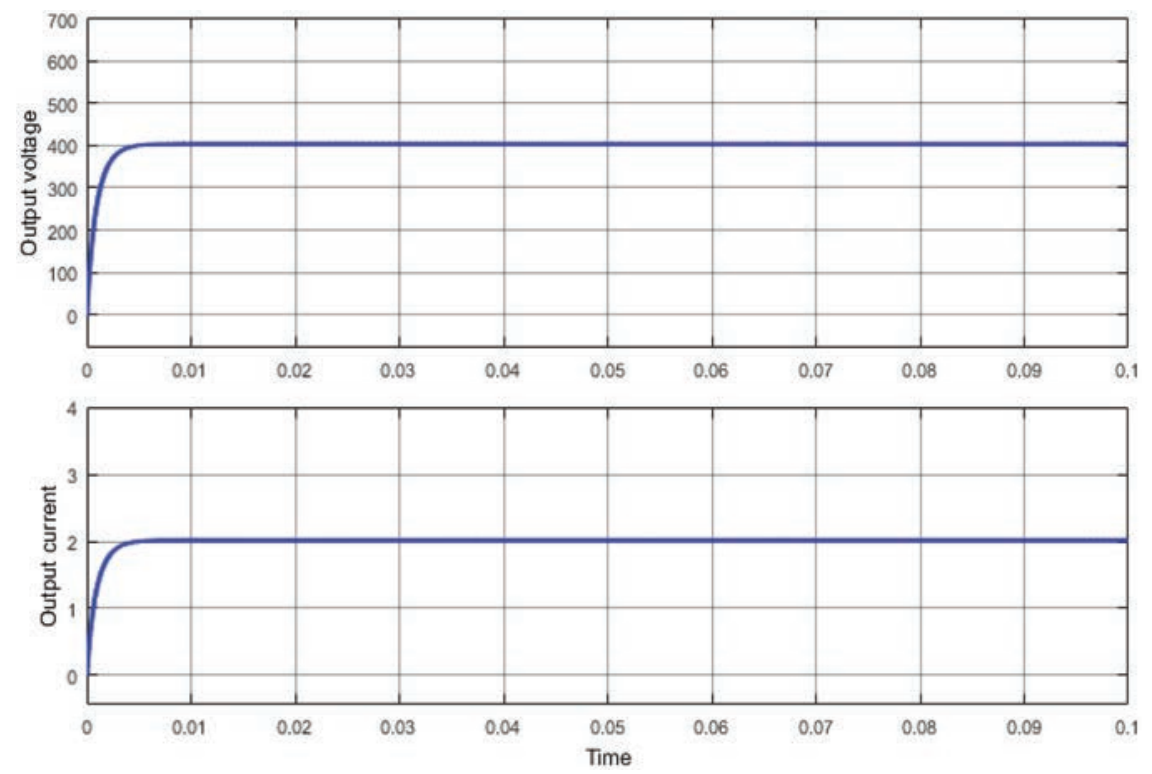

Figure 16 Output voltage and current for single stage boost rectifier and MOSFET's internal capacitance. 

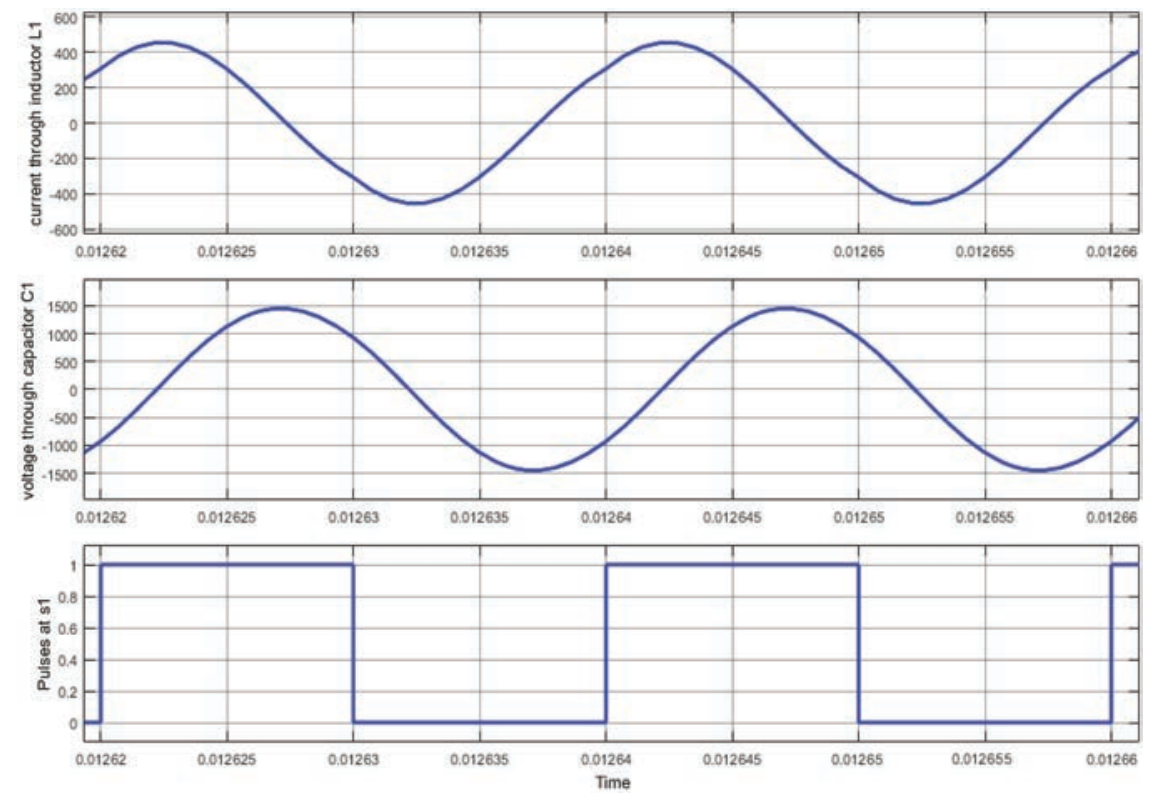

Figure 17 Current at the inductor L1, voltage across capacitor C1 and pulses at switch S1.
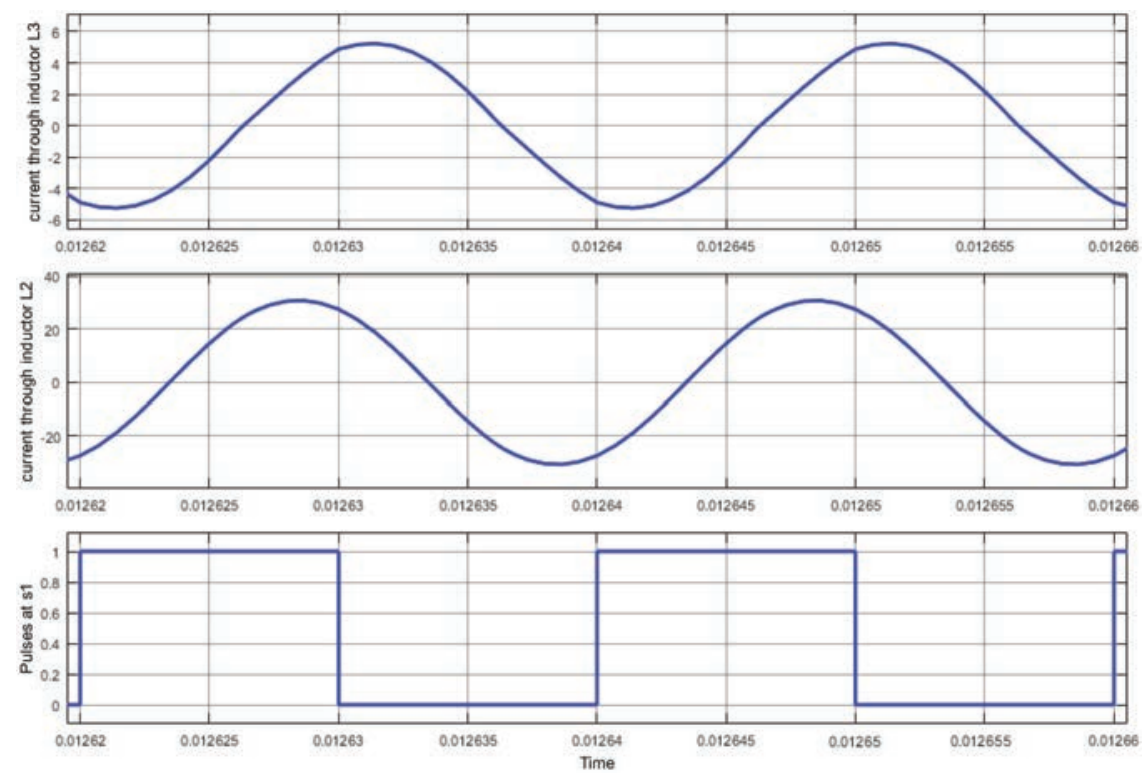

Figure 18 Current at the inductor L3, current across inductor L2 and pulses at switch S1. 
the four simulated topologies. The settling time for the circuits is $0.0045 \mathrm{sec}$, $0.004 \mathrm{sec}, 0.0025 \mathrm{sec}$ and $0.002 \mathrm{sec}$ respectively. Since the setting time for the proposed inductive power transfer circuit is lower than that of the other three topologies, it is determined that it can charge the EV battery at a faster rate and lesser time.

\section{Efficiency Calculations}

At resonant frequency condition, the magnetic energy would be equal to electrical energy, which is defined in terms of amplification coefficient $\lambda=\frac{I_{P}}{I_{r}}$.

$$
\begin{aligned}
\frac{1}{2} C_{P 1} V_{C P}{ }^{2} & =\frac{1}{2} L_{r} I_{r}{ }^{2} \\
\frac{1}{2} C_{P 2} V_{C P}{ }^{2} & =\frac{1}{2} L_{e q} I_{P}{ }^{2}
\end{aligned}
$$

Where $V_{C P}$ is the rms voltage of capacitance $C_{P}$ and $C_{P 1}, C_{P 2}$ are parallel capacitance representing $C_{P}$.

$$
\lambda=\frac{I_{P}}{I_{r}}=\sqrt{\frac{L_{r} C_{P 2}}{L_{e q} C_{P 1}}}
$$

For $\lambda=1$ the corresponding $L_{r}$ value obtained from Equation (10) is $9.10 \mu \mathrm{F}$. With the resulting voltage and current, the efficiency can be calculated as,

$$
\eta=\frac{P_{\text {out }}}{V_{\text {in }} I_{\text {in }}}
$$

The $\lambda$ is varied from 1 to 5 in Equation (10) with the variation of load resistance from $20 \Omega$ to $200 \Omega$. From the graph it is to be apparent that as $\lambda$ increases the efficiency increases with respect to the increase in load.

In the circuit with two secondary coils (Figure 1), with $\lambda=1$ the efficiency achieved is $65 \%$ as shown in Figure 19. While the efficiency of single secondary circuit (Figure 2), single stage boost circuit (Figure 3) and single stage boost with MOSFET internal capacitance circuit (Figure 4) are 70\%, $74 \%$ and $76 \%$ at $\lambda=1$ as shown in Figures 20,21 and 22. The efficiencies for different $\lambda$ values are listed in Table 2 for comparison.

Analyzing all the efficiency curves and the comparisons in Table 2, it is clear that the single stage boost rectifier without capacitor in secondary is preferable in terms of efficiency when compared to other topologies. 


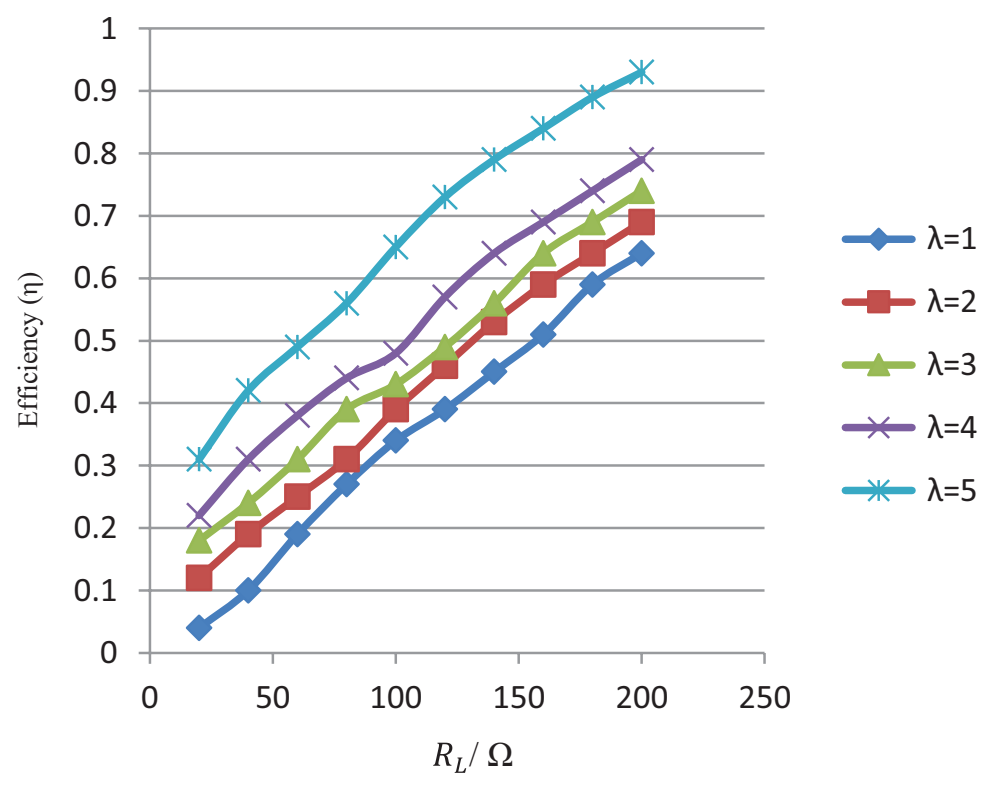

Figure 19 Efficiency curve of circuit with two secondary coils.

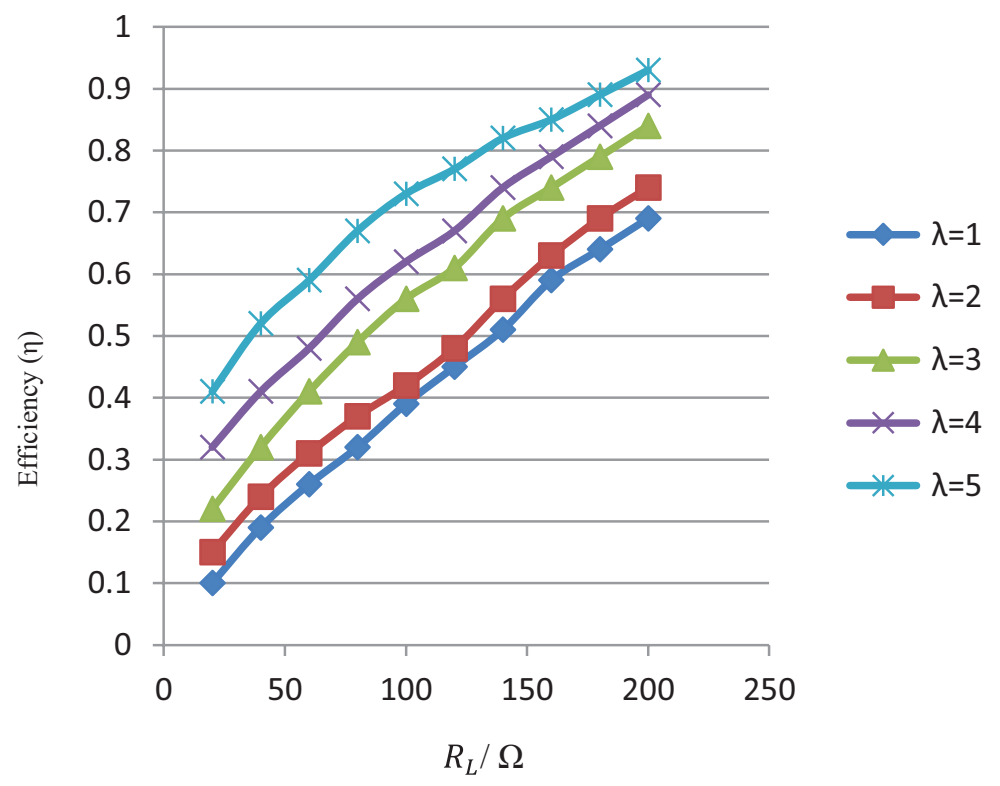

Figure 20 Efficiency curve of circuit with single secondary. 


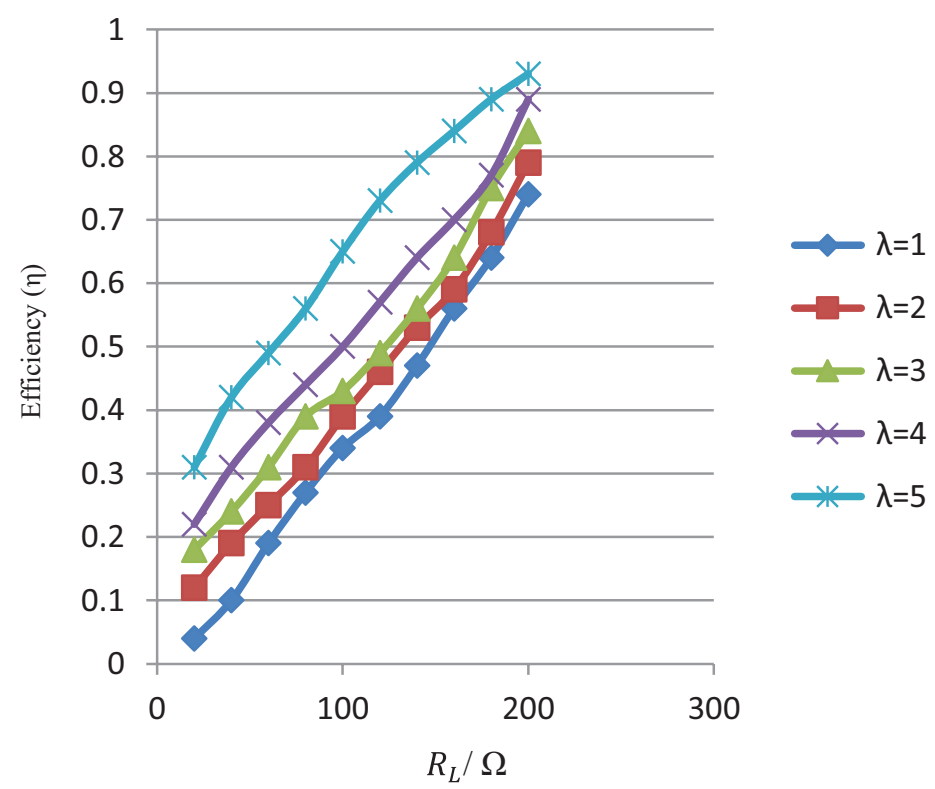

Figure 21 Efficiency curve of circuit with single stage boost rectifier circuit.

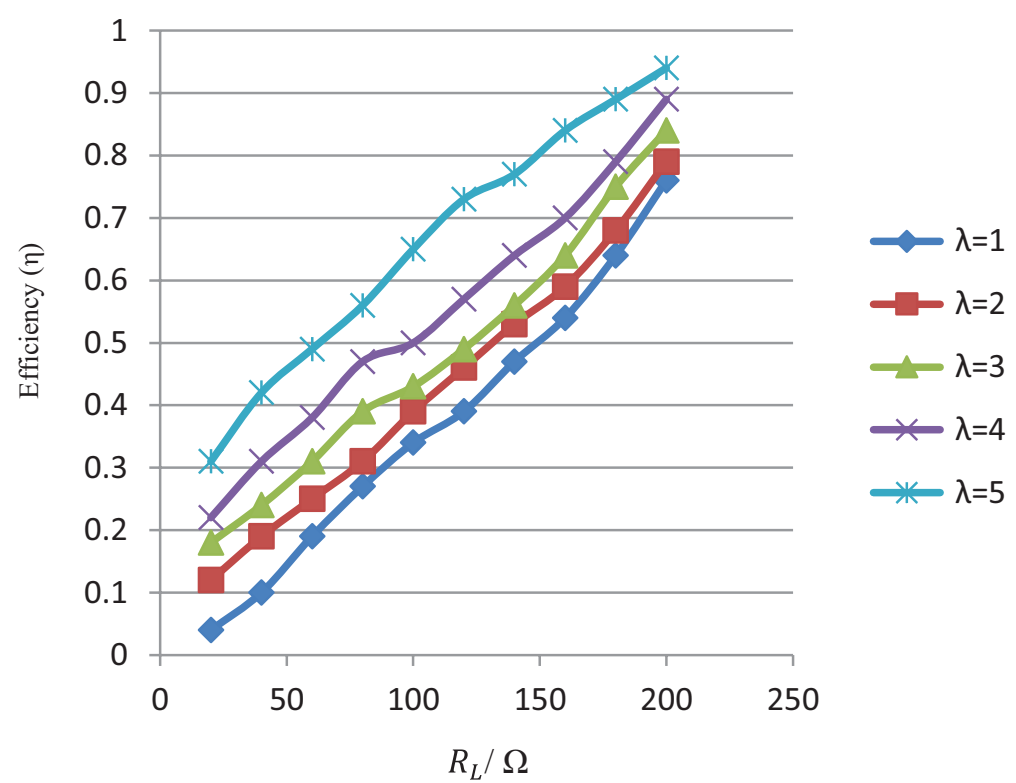

Figure 22 Efficiency curve of circuit with single stage boost and MOSFET internal capacitance. 
Table 2 Efficiency and inductance comparison for various $\lambda$

\begin{tabular}{ccccccccc}
\hline$\lambda$ & $\eta 1$ & $L_{r 1}$ & $\eta 2$ & $L_{r 2}$ & $\eta 3$ & $L_{r 3}$ & $\eta 4$ & $L_{r 4}$ \\
\hline 1 & $65 \%$ & $9.10 \mu \mathrm{F}$ & $70 \%$ & $9.10 \mu \mathrm{F}$ & $74 \%$ & $9.10 \mu \mathrm{F}$ & $76 \%$ & $9.10 \mu \mathrm{F}$ \\
\hline 5 & $93 \%$ & $249.75 \mu \mathrm{F}$ & $93 \%$ & $249.75 \mu \mathrm{F}$ & $94 \%$ & $249.75 \mu \mathrm{F}$ & $94 \%$ & $249.75 \mu \mathrm{F}$ \\
\hline
\end{tabular}

\section{Comparison of Results}

The comparison of all the four topologies are shown in Table 3. The comparison results prove that the single stage boost with MOSFET internal capacitance

Table 3 Comparison results

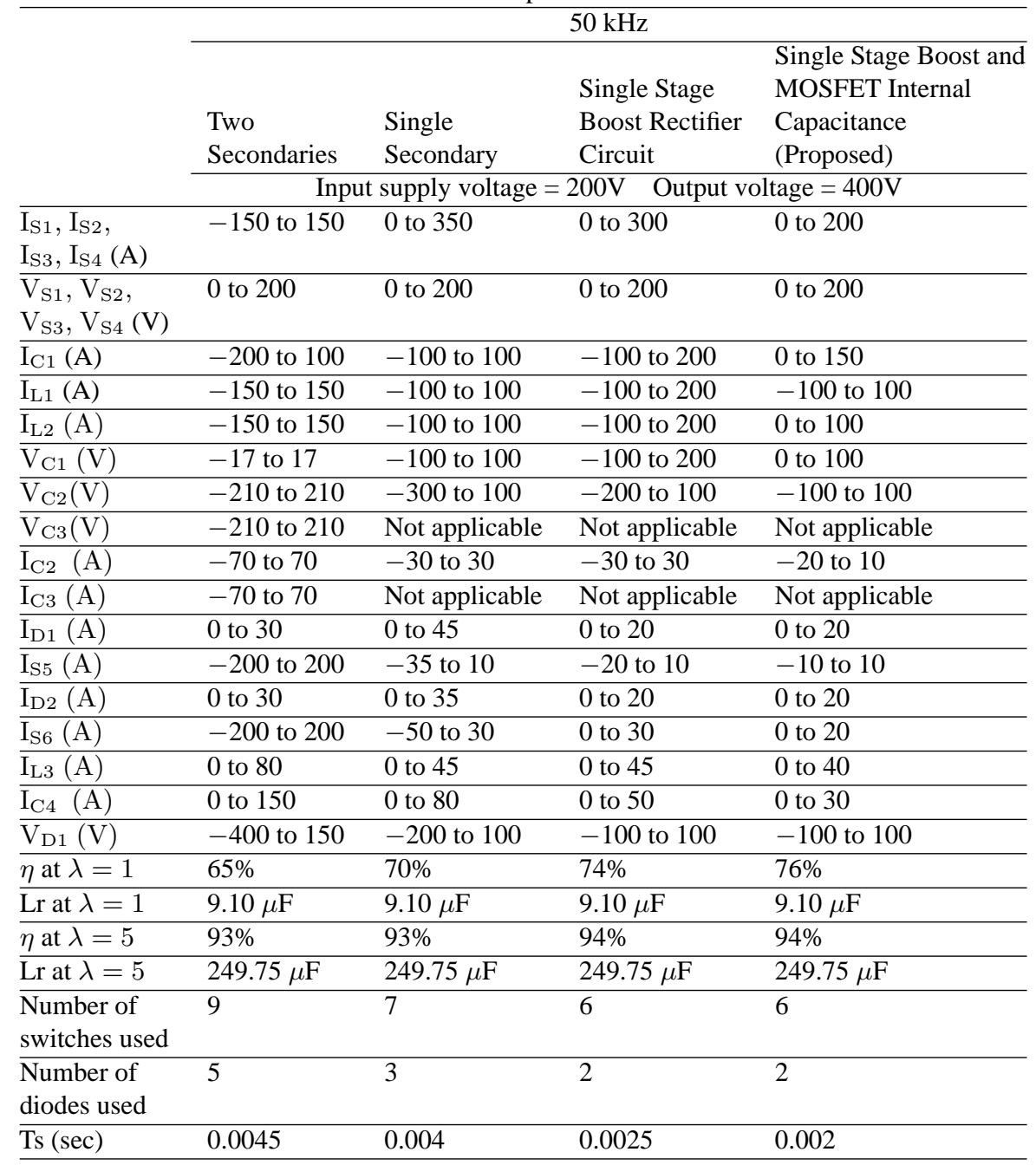


have a lower voltage and current stress, conduction loss compared to other topologies.

From Table 3 it is clear that the proposed circuit has less number of switches and diodes than the IPT with two [1] and one secondary topologies [14, 15]. The proposed circuit has one capacitor less than the IPT with single stage boost rectifier circuit. The voltage and current through the switches and diodes are comparatively lower in the proposed circuit, which evidently means that the voltage and current stress is also less in the proposed circuit. While comparing the settling time of the output voltage in the four circuits, the proposed circuit again has the least value ( $2 \mathrm{msec})$. Also, the proposed circuit has an efficiency of $94 \%$ at $\lambda=5$ and $76 \%$ at $\lambda=1$, which is the highest among the topologies discussed. Therefore, by analyzing Table 3 . it is evident that the proposed network can charge an EV faster with higher efficiency than the other three topologies.

\section{Hardware Results}

The simulated proposed topology was implemented in hardware in the laboratory with a step-by-step approach. The complete prototype was realized by integrating a resonant DC/AC converter, transmitter coil, receiver coil, and single stage boost rectifier circuit. The wireless coil consists of a transmitter and receiver coil. The receiver coil is wound in such a way so as to maximize the power transferred to the load side. The transmitter coil consists of 23 turns and the receiver consists of 30 turns. The Figure 23(a) illustrates the source voltage without filter and Figure 23(b) represent source voltage with filter. The Figure 24(b) given below represents the hardware implementation of the Inverter circuit.

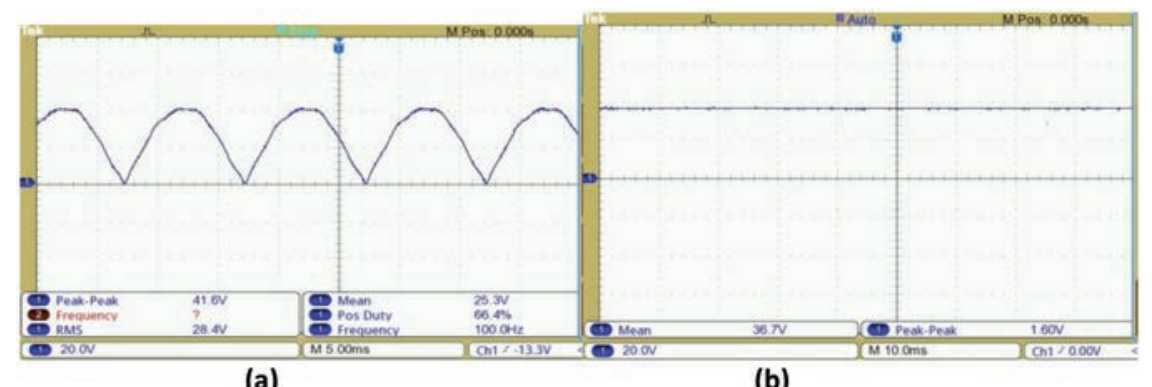

(a)

(b)

Figure 23 Output voltage of the diode bridge rectifier (a) without filter (b) with filter. 


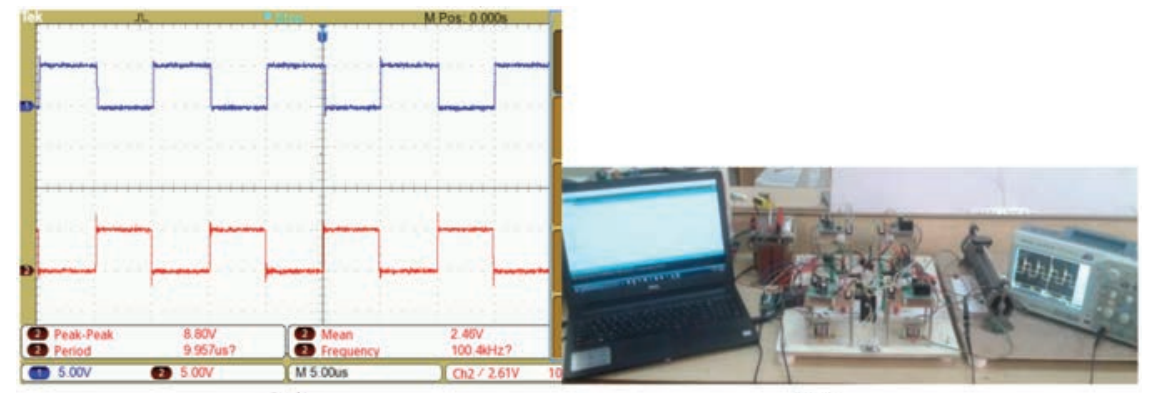

(a)

(b)

Figure 24 (a) Pulses generated from Arduino Uno (b) Hardware implementation of inverter circuit.

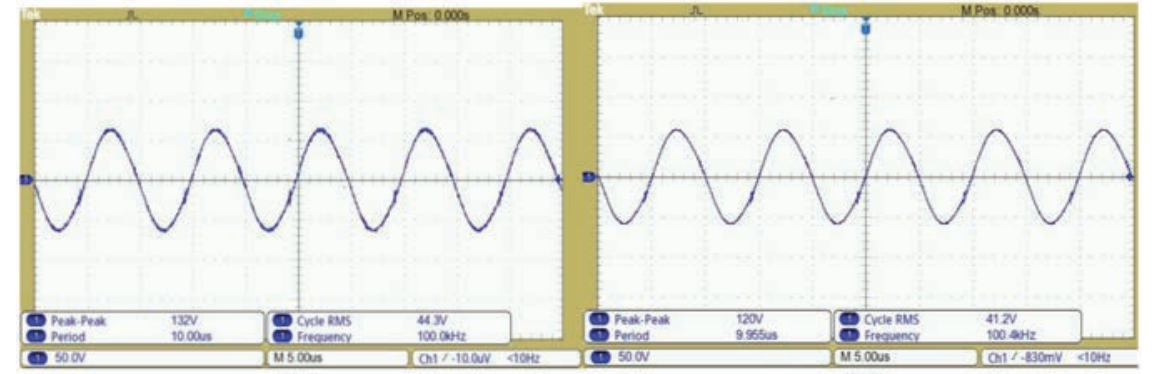

(a)

(b)

Figure 25 Output voltage across the (a) transmitter coil (b) receiver coil.

The single phase inverter is operated with $100 \mathrm{kHz}$ pulses generated from Arduino Uno as shown in Figure 24(a). The resonant converter (DC/AC) in the transmitter side shapes the current waveform as a sinusoidal wave at the transmitter side. MOSFET IRF640 (which has tolerance till $500 \mathrm{kHz}, 100 \mathrm{~V}$, $18 \mathrm{~A}$ ) are used as switches. The input for the inverter is $30 \mathrm{~V} \mathrm{DC}$, as shown in Figures 23 and 24 respectively. The output obtained at the load side is $132 \mathrm{~V}$ (Vp-p). Figure 25(a) and Figure 25(b) represent the output voltage across transmitter and receiver coil. The peak to peak voltage obtained is $130 \mathrm{~V}$ and $120 \mathrm{~V}$ in both the cases for $30 \mathrm{~V}$ DC input.

\section{Conclusion}

The inductive power transfer system is designed and simulated in various configurations such as double secondary, single secondary, single secondary 
with single stage boost rectifier circuit, single stage boost rectifier circuit without capacitance in secondary. The simulated and hardware results of output voltage and current for all four topologies are analyzed and presented. It is verified that boost rectifier circuit without capacitance in secondary has the least device count (switches, diodes and capacitors). The proposed topology has lower voltage and current stress across the switches, higher efficiency, lower switching losses, less settling time and is simpler in design and hence is more suited for wireless EV battery charging applications.

\section{References}

[1] Zaheer, A., Neath, M., Beh, H. Z. Z. and Covic, G. A. (2017). "A dynamic EV charging system for slow moving traffic applications," IEEE transactions on transportation electrification, 3(2), 354-369.

[2] George, R., Sreekala, M. and Deepa, K. (2016). "Single-Stage Boost Rectifier for Wireless Charging of Portable Devices Through Magnetic Resonant Coupling." In Artificial Intelligence and Evolutionary Computations in Engineering Systems (pp. 443-452). Springer, New Delhi.

[3] George, R., Manmadhan, S. and Deepa, K (2016). "Implementation of wireless charging system using single stage power conditioning circuit at receiver," International Journal of Control Theory and Applications 9(16).pp.7939-7950.

[4] Aditya, K. and Williamson, S. S. (2017). "A review of optimal conditions for achieving maximum power output and maximum efficiency for a series-series resonant inductive link," IEEE transactions on transportation electrification, 3(2), 303-311.

[5] Li, S. and Mi, C. C. (2015). "Wireless power transfer for electric vehicle applications," IEEE journal of emerging and selected topics in power electronics, 3(1), 4-17.

[6] Feng, R., Czarkowski, D., De Leon, F. and Mude, K. (2017). "Optimal design of resonant coupled multi-receiver wireless power transfer systems," In Industrial Technology (ICIT), 2017 IEEE International Conference on (pp. 1561-1566). IEEE.

[7] Bertoluzzo, M., Naik, M. K. and Buja, G. (2012). "Preliminary investigation on contactless energy transfer for electric vehicle battery recharging," In Industrial and Information Systems (ICIIS), 2012 7th IEEE International Conference on (pp. 1-6). IEEE. 
[8] Wang, C. S., Stielau, O. H. and Covic, G. A. (2005). "Design considerations for a contactless electric vehicle battery charger," IEEE Transactions on industrial electronics, 52(5), 1308-1314.

[9] O'brien, K., Scheible, G. and Gueldner, H. (2003). "Design of large airgap transformers for wireless power supplies," In Power Electronics Specialist Conference, 2003. PESC'03. 2003 IEEE 34th Annual (Vol. 4, pp. 1557-1562). IEEE.

[10] Sabuj Das Gupta, Md. Shalimar Islam, Kawser Md. Nuronnabi and Mohammad SakibHossain (2012). "Design and Implementation of Cost Effective Wireless Power Transmission Model”, International Journal of Scientific and Research Publications, Volume 2, Issue 12, December 2012.

[11] Hasanzadeh, S., Vaez-Zadeh, S. and Isfahani, A. H. (2012). "Optimization of a contactless power transfer system for electric vehicles," IEEE Transactions on Vehicular Technology, 61(8), 3566-3573.

[12] Li, X., Tsui, C. Y. and Ki, W. H. (2015). “A $13.56 \mathrm{MHz}$ wireless power transfer system with reconfigurable resonant regulating rectifier and wireless power control for implantable medical devices," IEEE Journal of Solid-State Circuits, 50(4), 978-989.

[13] Raju, S., Li, X., Lu, Y., Tsui, C. Y., Wing-Hung, K., Chan, M. and Yue, C. P. (2014). "Efficient wireless power transmission technology based on above-CMOS integrated (ACI) high quality inductors," In Electron Devices Meeting (IEDM), 2014 IEEE International (pp. 12-4). IEEE.

[14] Zhou, J., Wu, F., Zhang, R. and Dai, X. (2014). "Design and analysis of the LCL resonant convertor in inductive Power Transfer system," In Power Electronics and Application Conference and Exposition (PEAC), 2014 International (pp. 1271-1276). IEEE.

[15] Dieckerhoff, S., Ruan, M. J. and De Doncker, R. W. (1999). "Design of an IGBT-based LCL-resonant inverter for high-frequency induction heating," In Industry Applications Conference, 1999. Thirty-Fourth IAS Annual Meeting. Conference Record of the 1999 IEEE (Vol. 3, pp. 20392045). IEEE.

[16] Chun Qiu, K. T, Chau, Chunhua Liu, C. C. and Chan, (2013). Overview of wireless power transfer for electric vehicle charging, 2013 World Electric Vehicle Symposium and Exhibition (EVS27), (pp. 1-9).

[17] Jang, Y. J. (2018). "Survey of the operation and system study on wireless charging electric vehicle systems," Transportation Research Part C: Emerging Technologies. 


\section{Biographies}

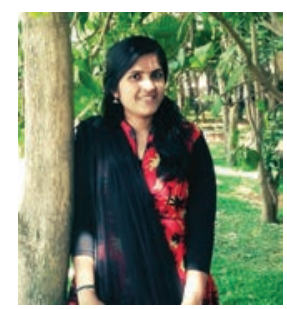

Sweya Sasikumar, born in 1994 in Kerala, India, received her M.Tech. degree in Power Electronics Engineering in 2018 from Amrita School of Engineering, Bengaluru, India, and her B.Tech. degree in Electrical and Electronics Engineering in 2016 from Kannur University. Her areas of interests include Power Electronics and Control system.

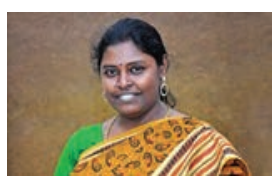

K. Deepa graduated from Alagappa Chettiar college of engineering and Technology, T.N, India in 1998. She obtained M.Tech degree from Anna University, Guindy campus, T.N, India in 2005. She received Doctoral degree from Jawaharlal Nehru Technological University, Anantapur, A.P, India in 2017.

Currently she is working as Assistant professor in Electrical and Electronics Engineering Department, Amrita School of Engineering, Amrita Vishwa Vidyapeetham University, Bangalore, Karnataka, India. She has 20 years of teaching experience. She is a life Member of IETE and ISTE, India and a senior member of IEEE. She has authored two textbooks on "Electrical Machines" and "Control Systems". She has published 27 international journal paper, 31 papers in international conference and 6 papers in national conference. 15 M.Tech Degrees were awarded under her guidance. She is the advisor for the IEEE-PES \& IAS student branch joint chapter and advisor for IEEEWIE in Amrita School of Engineering, Bengaluru from 2015. She is also joint treasurer for 2018 EXECOM of IEEE PES Bangalore chapter. Her areas of interests include Power electronics, Renewable energy technologies and Control Engineering. 